\title{
Ionization Efficiency Curves of Acetylene by Electron Impact
}

\author{
Isao H. Suzuki* and Kogoro Maeda*
}

(Received 18 October 1977)

\begin{abstract}
Ionization efficiency curves have been measured for the ions including $\mathrm{CH}_{2}{ }^{+}$produced from acetylene by monoenergetic electron impact over ranges of about $10 \mathrm{eV}$ near their appearance thresholds. The total ionization efficiency curve shows breaks at the energies in agreement with the ionization potentials determined by photoelectron spectroscopy. Other breaks in the curve were found to correspond to autoionizing states. The appearance potential of $\mathrm{C}_{2} \mathrm{H}^{+}$almost agrees with that by photoionization mass spectrometry. The potentials of other fragment ions are not always close to those by previous electron impact experiments.
\end{abstract}

\section{Introduction}

Electronic orbital energies of acetylene were calculated by various molecular orbital methods, and the calculated energies were compared with ionization potentials (I. P.) determined by experiments.1-5)

Photoelectron spectroscopy (P. E. S.) provided the accurate values of higher I. P.'s of $\mathrm{C}_{2} \mathrm{H}_{2}$ as well as the first one.6) Photoionization efficiency curves were measured by a technique of photoionization mass spectrometry (P. I. M.),7-13) and ionization efficiency curves (I.E. C.) were also measured by use of electron beams. ${ }^{14-24)}$ Those curves suggested that indirect ionization considerably contributes to the ionization of $\left.\mathrm{C}_{2} \mathrm{H}_{2} .9,10,13,17-19\right)$ The contribution near ionizing threshold was clarified by the re- sults of P. I. M., which showed that vibrational excited states in the high Rydberg states converging to the first I. P. autoionize to the vibrational ground or lower excited states in the electronic ground state of the ion. 10,13) However, it remains ambiguous what kind of states gives rise to indirect ionization in the higher energies. Further, the studies by impact of monoenergetic electron beams (M.E.I.) have been limited to the first ionizing threshold.14-16)

In the present study the I.E.C. 's of all the possible ions produced from $\mathrm{C}_{2} \mathrm{H}_{2}$ have been measured over ranges of about $10 \mathrm{eV}$ below and above their appearance thresholds by use of a monoenergetic electron beam.25-27) A total I. E. C. is calculated over the range from 11 to $22 \mathrm{eV}$, and I. P. 's are obtained from the breaks of the curve. 
A new method to clarify an effect of indirect ionization is proposed, and autoionizing states are found. The appearance potentials (A. P.) for fragment ions are determined from the I. E. C.' 's.

\section{Experimental}

Measurements were carried out by use of the apparatus described in previous papers. 25, 27) In observing the I. E. C. each memory channel in the pulse height analyzer corresponded to each electron energy, while in obtaining the mass spectra the memory channels were used as a mass scale. The energy of the bombarding electron beam(f. w. h. m. : $0.15 \mathrm{eV}$ ) was scanned from 10.5 to $23.0 \mathrm{eV}$ with $0.05 \mathrm{eV}$ intervals for the parent ion and from 16.0 to $25.0 \mathrm{eV}$ with the same intervals for $\mathrm{C}_{2} \mathrm{H}^{+}$. The energy was scanned over ranges of about 10 $\mathrm{eV}$ near their appearance thresholds with $0.1 \mathrm{eV}$ intervals for other fragment ions $\left(\mathrm{C}_{2}{ }^{+}, \mathrm{CH}_{2}{ }^{+}, \mathrm{CH}^{+}, \mathrm{C}^{+}\right.$and $\left.\mathrm{H}^{+}\right)$. Ion counts of about 160 c.p.s. were obtained for $\mathrm{C}_{2} \mathrm{H}_{2}{ }^{+}$ at $23 \mathrm{eV}$ and noise counts were less than 0.1 c. p. s..

The electron energy was calibrated by using the $12.13 \mathrm{eV}$ threshold for Xe. The measured I.E.C. 's were processed by a computer in order to check their reproducibilities and to estimate a standard deviation at every energy.26)

The sample gas acetylene (purity: 99.6 $\%$ ) was supplied at about $5 \times 10^{-6}$ Torr.

\section{Results and Discussion}

\subsection{Total Ionization Efficiency Curve}

Since all ions are produced via their parent ions or excited states of the neutral parent molecules in the case of electron impact, information on the parent ion and on the neutral excited states is contained in the total I.E.C. but not in the I.E.C. of the parent ion only.25-27) A total I. E. C. of $\mathrm{C}_{2} \mathrm{H}_{2}$ is shown over the range of the bombarding electron energy from 11.0 to $21.5 \mathrm{eV}$ in Fig 1. The curve is a summation composed of the I.E. C. 's of $\mathrm{C}_{2} \mathrm{H}_{2}{ }^{+}, \mathrm{C}_{2} \mathrm{H}^{+}$ and the $\mathrm{C}_{2} \mathrm{H}_{2}{ }^{+}$including ${ }^{13} \mathrm{C}$. Other fragment ions were neglected in the summation because these ions contributed to the total intensity of ions less than $0.3 \%$ below $22 \mathrm{eV}$. In the calculation of the curve, a mass discrimination effect of the present experi. mental system was corrected using the mass spectrum at $50 \mathrm{eV}$ in A.P. I. Table.28) (After this correcton, it was found that the procedure is unnecessary because the correction factor was very small, 0.02. At $22 \mathrm{eV}$ this factor corresponds to only $0.5 \%$ of the total ion intensity.) As seen at the upper part with an expanded scale, the curve shows an onset at $11.4 \mathrm{eV}$ followed by many breaks. The values of the onset and breaks are listed in Table 1 as well as those obtained by other investigators.

Previous investigators had showed only figures of curves but did not propose the values of energy.6,9,16) The present authors estimated those values from the figures shown in the original papers.

The onset at $11.4 \mathrm{eV}$ is in agreement with the values of previous photoionization experiments, ${ }^{6-13}$ ) in which the onset was assigned to the vibrational ground state in the electronic ground state of $\mathrm{C}_{2} \mathrm{H}_{2}{ }^{+}, 2 \mathrm{I}_{u}$ $6,8-10,13)$.

The break at $11.8 \mathrm{eV}$ is supposed to correspond to the second vibrational excited state in the ${ }^{2} \Pi_{u}$ state as seen in the results 
Table 1: Ionization potentials and breaking-point energies of $\mathrm{C}_{2} \mathrm{H}_{2}$ (in units of eV). The symbols parenthesized denote the electronic states of $\mathrm{C}_{2} \mathrm{H}_{2}{ }^{+}$.

\begin{tabular}{|c|c|c|c|c|c|c|c|}
\hline worker & Baker et al. & $\begin{array}{l}\text { Dibeler } \\
\text { et al. }\end{array}$ & Collin & $\begin{array}{l}\text { Melton } \\
\text { et al. }\end{array}$ & $\begin{array}{l}\text { Momigny } \\
\text { et al. }\end{array}$ & Lossing & $\begin{array}{l}\text { Present } \\
\text { Authors }\end{array}$ \\
\hline method & P.E.S. & P.I.M. & R.P.D. & R.P.D. & $\begin{array}{l}\text { First } \\
\text { Deriv. }\end{array}$ & M.E.I. & M.E.I. \\
\hline$\left({ }^{2} \Pi_{u}\right)$ & $\begin{array}{l}11.40 \\
11.63^{*}\end{array}$ & $\begin{array}{l}11.406 \\
11.663\end{array}$ & 11.50 & $\begin{array}{l}11.4 \\
11.7\end{array}$ & 11.41 & $\begin{array}{l}11.39 \\
11.6 *\end{array}$ & $11.4 \pm 0.1$ \\
\hline & $11.87^{*}$ & $\begin{array}{l}11.864 \\
12.7^{*}\end{array}$ & & 12.2 . & & $11.8^{*}$ & $\begin{array}{l}11.8 \pm 0.1 \\
12.3 \pm 0.2\end{array}$ \\
\hline & & 13. $2^{*}$ & 13.25 & 13.2 & 13.41 & & $13.4 \pm 0.2$ \\
\hline & & $14.7^{*}$ & 14.40 & 14.5 & 14.28 & & $14.3 \pm 0.2$ \\
\hline$\left({ }^{2} \Sigma_{0}\right)$ & 16.36 & & 16.95 & 17.0 & 16. 40 & & $16.35 \pm 0.15$ \\
\hline & & & & & 17.43 & & $17.45 \pm 0.15$ \\
\hline$\left({ }^{2} \Sigma_{u}\right)$ & 18. 38 & & & & 18. 40 & & 18. $35 \pm 0.2$ \\
\hline Ref. & 6 & 9 & 17 & 18 & 19 & 16 & - \\
\hline
\end{tabular}

* denotes the value estimated by the present authors. R.P.D. indicates the retarding potential difference method. First Deriv. indicates a technique to obtain information for the first derivative curve of the I.E.C.

of P.E.S.6), of P.I.M. 8-10,13) and of the monoenergetic electron impact by Lossing 16). The first excited state of $11.6 \mathrm{eV}$ does not appear clearly in this study. This is probably due to the smearing out by the energy spread of the electron beam, by the higher transition probability to the vibrational ground state and by the autoionization from vibrational excited states in high Rydberg states. Several years ago, Brion15) and Collins et al.14) suggested that the relative transition probabilities to the lower vibrational states in the electronic ground state in the ionization of $\mathrm{C}_{2} \mathrm{H}_{2}$ by electron impact are quite different from those by photon impact 8-10,13); the transition probability to the vibrational ground state is considerably lower than that to the first excited state by electron impact 14,15 ).
Lossing offered the evidence against that suggestion on the basis of his result 16 ). The present result supporrts the evidence by Lossing because the slope starting at $11.4 \mathrm{eV}$ in the total I.E.C. is the steepest in the region near threshold, that is, the transition probability to the ground state is the highest in this region.

The total I.E.C. shows the trend to decrease in slope above $15.5 \mathrm{eV}$ and starts to increase again at $16.35 \mathrm{eV}$. This energy is nearly equal to $16.36 \mathrm{eV}$ in P.E.S., of which the state was assigned to ${ }^{2} \Sigma_{g}$ of $\mathrm{C}_{2} \mathrm{H}_{2}{ }^{+6}$ ). The curve also shows an upward break at $18.35 \mathrm{eV}$, which corresponds to ${ }^{2} \sum_{u}$ of $\mathrm{C}_{2} \mathrm{H}_{2}{ }^{+}$on account of the result by P.E. S.6)

Botter et al. measured the photoionization efficiency curves for ions produced 
from $\mathrm{C}_{2} \mathrm{H}_{2}$ and $\mathrm{C}_{2} \mathrm{D}_{2}$ using the technique of P.I.M.9) Then they argued that the acetylene molecules have autoionizing states around 13.5 and $15 \mathrm{eV}$ and that the deuterated molecule autoionizes with higher probability than the non-deuterated molecule in these regions. The latter argument is supported by the expectation that an autoionizing process is likely to surpass the predissociation to neutral species in the case of heavier detaching species more frequently than in the case of lighter one 29,30 ). Using electron impact, Collin, 17) Melton et al. 18) and Momigny et al.19) obtained the energy values of the states of $\mathrm{C}_{2} \mathrm{H}_{2}$ or $\mathrm{C}_{2} \mathrm{H}_{2}{ }^{+}$in the region of 12 to $14.5 \mathrm{eV}$. The I.E.C. by electron impact occasionally contains fine structures caused by temporary negative ion states. Those structures are generally seen as peaks or dips due to resonance phenomenon.31) Then, the states which appeared in the region from 12 to $15 \mathrm{eV}$ were not assigned to negative ion states on account of structural features in the I.E.C.'s. Since no structure appeared in this region in P.E.S.,6) these states are supposed to be autoionizing states. 32) If the autoionizing states are isolated from one another, the states should give peaks in the curve of P.I.M. and humps in the total I.E.C. Since bands and upward breaks appeared in the former and latter curves,9,17-19) the states are supposed to be located close together to form bundles. The states of the bundles may be related to a bent structure of the excited acetylene. (When the geometry of an excited states is different from that of the ground state, the Franck-Condon principle allows transition into many vibrational states in the excited state to occur with high probability and to bring about a band in the spectrum. If the excited state is an autoionizing state, a band will appear in the curve of P. I. M.)

In order to clarify the information on the autoionizing states, the following calculation was carried out. The curve of P. I. M. by Botter et al. was integrated with respect to the energy.9) The P. E. spectrum by Baker et al. was integrated with respect to the energy twice on the assumption that the transmission efficiency of electrons was proportional to the energy of detected electrons in the energy analyzer.6) These two integrated curves (named C.I.E.C.'s.) should be approximately equal to the total I.E.C. by electron impact when only direct ionization occurs. The C.I.E.C.'s were normalized at $13.0 \mathrm{eV}$ in reference to the total I.E.C. shown in Fig. 1. Then the difference curve $(\mathrm{D} \nu)$ between the C.I.E.C.'s from P.I. M. and from P.E.S. and another difference curve (De) between the total I.E.C. and the C.I.E.C. from P.E.S. were calculated.33) The obtained curves are shown in Fig. 2a) over the energy range from 11.5 to $17.0 \mathrm{eV}$. The curves, $\mathrm{D} \nu$ and $\mathrm{De}$, were also calculated from the C.I.E.C.'s normalized at $19.0 \mathrm{eV}$ and were shown in Fig. $2 \mathrm{~b}$ ) over the range from 16 to $20 \mathrm{eV}$.

The curve $\mathrm{D} \nu$ seems to show increases in slope near the energies indicated in Table 1 (12.7, 13.2 and $14.7 \mathrm{eV})$. The curve De shows increases in slope near the energies obtained from the breaks in Fig. 1 (12.3, 13.4 and $14.3 \mathrm{eV}$ ). This latter curve also increases at about $12.7 \mathrm{eV}$ in agreement with the result of P.I.M. (The accuracy of the increasing points is about $0.2 \mathrm{eV}$ in energy.) Although other increases are perceptible, such as, at $13.75,14.6$ and $15.2 \mathrm{eV}$, 
those are less than the error bars. The break at $12.3 \mathrm{eV}$ did not appear in the curve from P.I.M., but the break was measured in the experiments of electron impact by other investigators as well as in the present study. 18,32) This state is supposed to be an autoionizing state to which transition is optically forbidden from the neutral ground state.

The two curves in Fig. 2 are quite different in shape from each other around $14 \mathrm{eV}$. This fact indicates that acetylene molecule has autoionizing states optically forbidden in this region. This is consistent with the measurement by Lichten, who obtained a neutral state at $14.4 \mathrm{eV}$ by detecting the metastable species produced by electron impact. 34) The state at $14.2 \mathrm{eV}$, therefore, is the optically forbidden state. The break at $14.7 \mathrm{eV}$ in the $\mathrm{D} \nu$ suggests that an optically allowed autoionizing state exists in the region.

The present authors calculated energy values of autoionizing states using assumed quantum defects.

$$
\mathrm{Ea}=\mathrm{I} . \mathrm{P} .-\frac{\mathrm{Ry}}{(\mathrm{n}-\delta)^{2}},
$$

where Ry is the Rydberg constant, $n$ denotes a quantum number as a linear molecule and $\delta$ means a quantum defect. The I.P. values by P.E.S. were employed.5,6) The values of the quantum defect were assumed to be $0.95,0.9,0.7$ and 0.5 for $\sigma_{g}, \sigma_{u}, \pi_{u}$ and $\pi_{g}$ orbitals, respectively, on account of the following finding; the photoabsorption

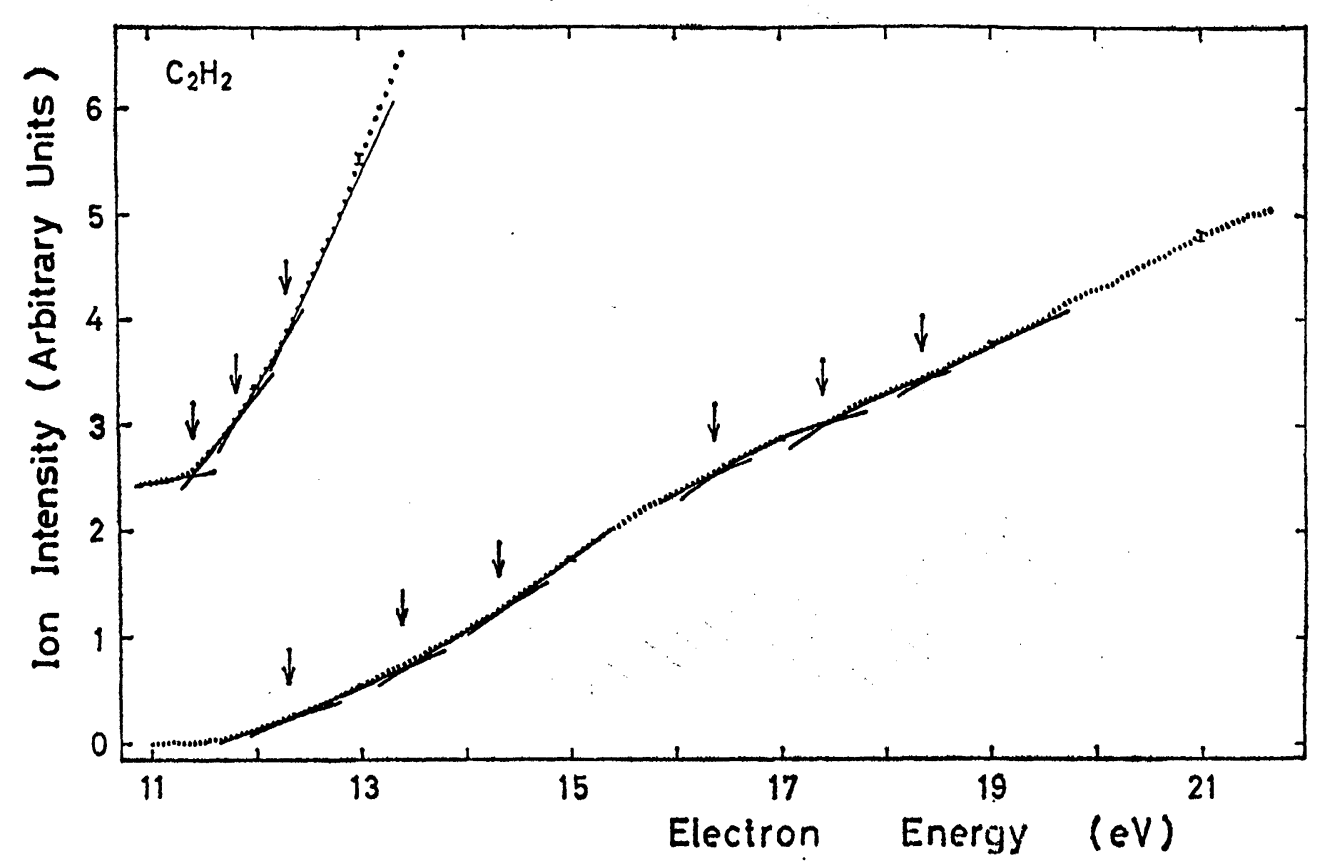

Fig. 1: Total ionization efficiency curve of $\mathrm{C}_{2} \mathrm{H}_{2}$. The curve from 11.0 to $13.5 \mathrm{eV}$ is also displayed in an expanded scale at the upper part. Bars denote statistical errors. 


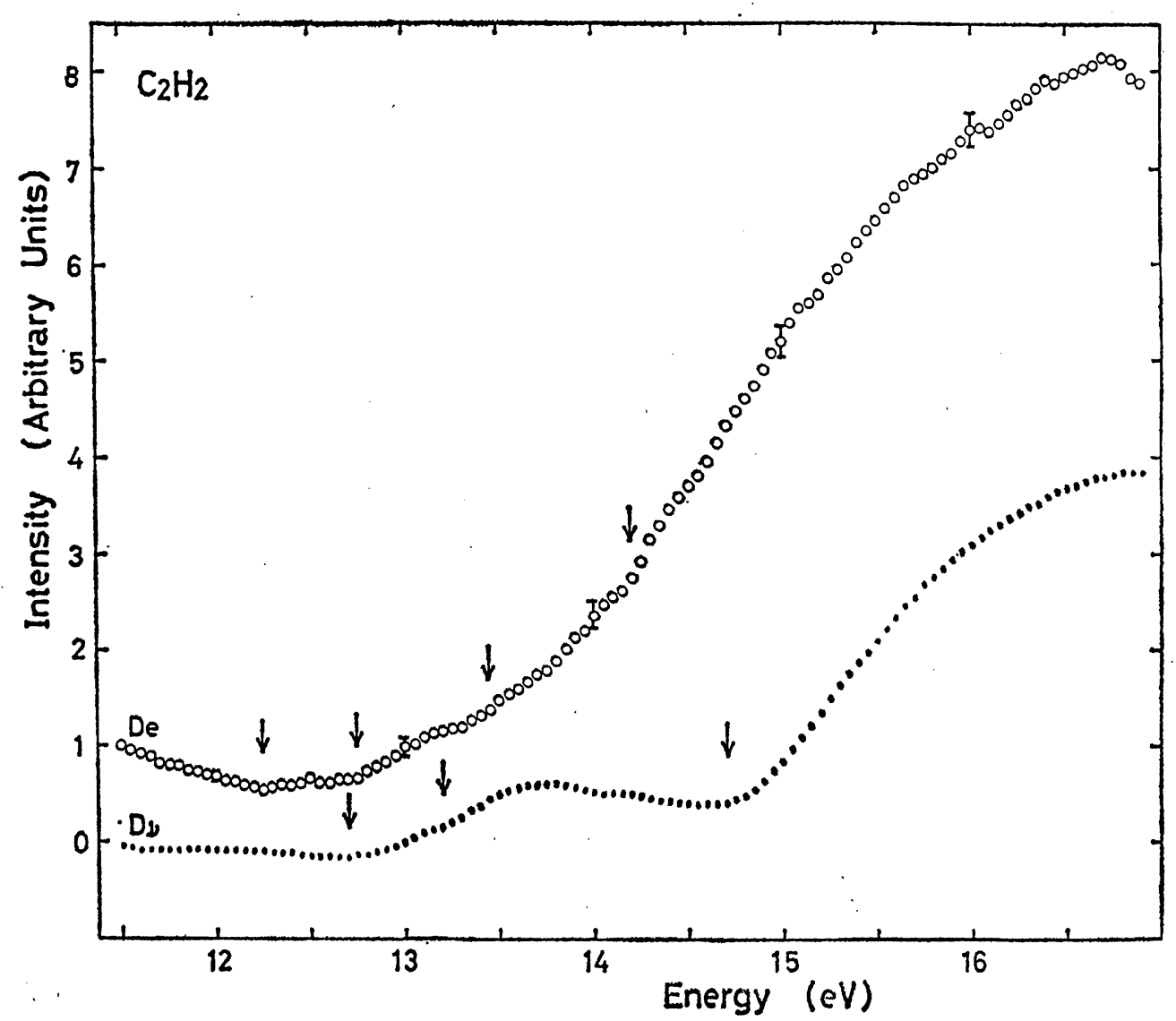

Fig. 2a): Difference curves between corresponding ionization efficiency curves (C.I.E.C.) of .. $\mathrm{C}_{2} \mathrm{H}_{2}$. De indicates the curve $\mathrm{w}^{\mathrm{w}}$ wich is the total I.E.C. in the present study minus the C.I.E.C. fromP.E.S. (Ref. 6). D $\nu$ indicates the curve which is the C.I.E.C. from P.I.M. (Ref. 9) minus the C.I.E.S. from P.E.C. Bars denote statistical errors.

measurement of acetylene below the first I. P. provided the values of the defect $(0.95$ and 0.5 ) for $\sigma_{g}$ and $\pi_{g}$ orbitals. 35,36 )

Then we tentatively assigned the energy values obtained from the $\mathrm{De}$ and $\mathrm{D}$, to these calculated values (Table 2). In the assignment, the following supposition was taken into account. Firstly, we supposed that the excitation of one electron is more probable than that of two electrons, that is, the transitions to such excited stated as $\cdots \cdots\left(2 \sigma_{u}\right)^{2}\left(3 \sigma_{g}\right)^{2}\left(1 \pi_{u}\right)^{2}$ (n $\sigma$ or $\left.n^{\prime} \pi\right)^{2}$ were ignored. 32) Secondly, according to the correlation diagram by Walsh,37) $1 \pi_{g}$ orbital is more stable in a bent structure than the linear structure and $1 \pi_{u}$ orbital seems to have a little stable character in a bent structure, while $3 \sigma_{g}$ and $3 \sigma_{u}$ orbitals are the most stable in the linear structure. If these situations hold for the characteristics of 


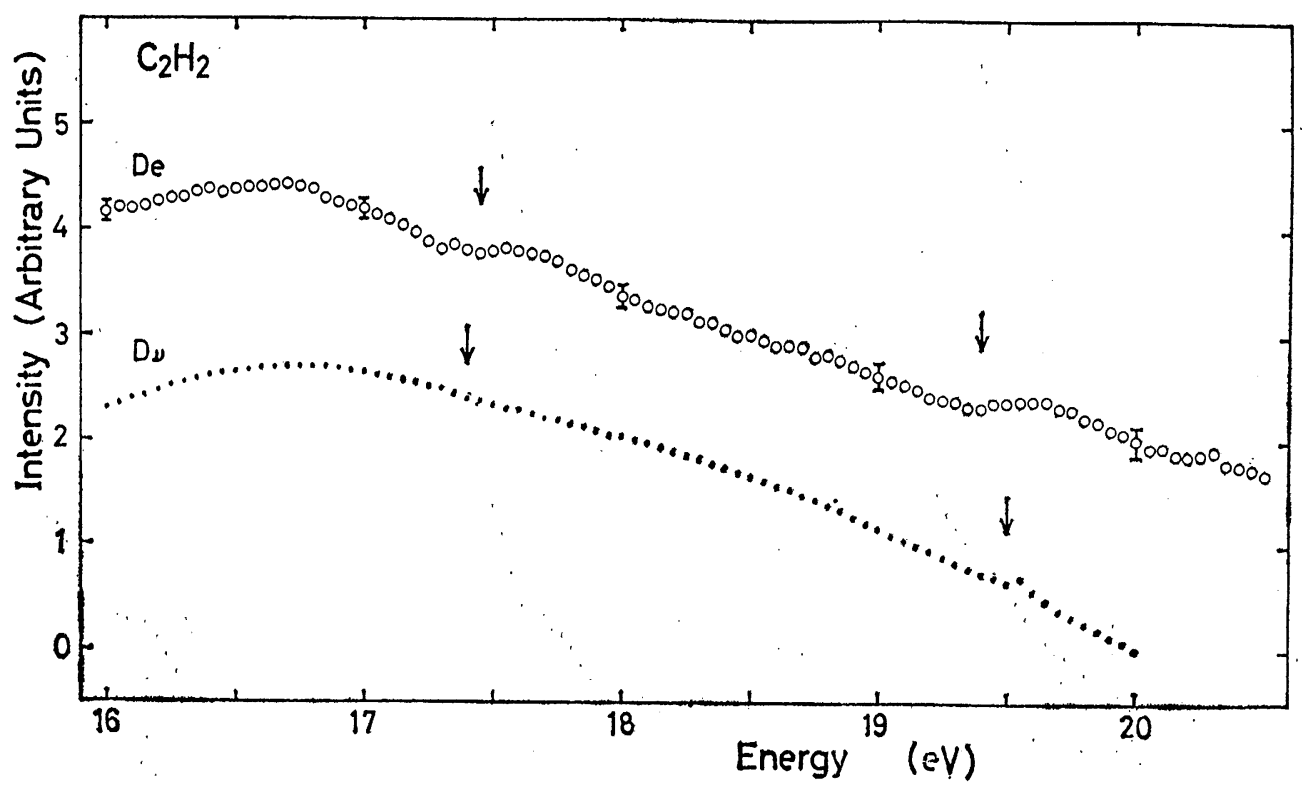

Fig. 2b): Difference curves between corresponding ionization ef ficiency curves (C.I.E.C.) of $\mathrm{C}_{2} \mathrm{H}_{2}$. Bars denote statistical errors. See the caption of Fig. 2a) with respect to De and Dy.

Table 2: A tentative assignment of autoionizing states of $\mathrm{C}_{2} \mathrm{H}_{2}$. In the calculation of De and $D_{\nu}$, the data by photon impact methods (Refs. 6 and 9) were used. The accuracy in $D_{\nu}$ and De is about $0.2 \mathrm{eV}$.

\begin{tabular}{|c|c|c|c|c|c|c|c|c|c|}
\hline \multicolumn{3}{|c|}{ Experiment } & \multicolumn{7}{c|}{ Calculation } \\
\hline $\begin{array}{c}\text { photon } \\
\text { D }\end{array}$ & $\begin{array}{c}\text { electron } \\
\text { De }\end{array}$ & $\begin{array}{c}\text { bundle } \\
\text { or } \\
\text { not }\end{array}$ & $\begin{array}{c}\text { allowed } \\
\text { or } \\
\text { forbidden }\end{array}$ & $\begin{array}{c}\text { energy } \\
(\mathrm{eV})\end{array}$ & $\delta$ & $\mathrm{n}$ & configuration & $\begin{array}{c}\text { term } \\
\left(\mathrm{D}_{\propto h}\right)\end{array}$ & $\begin{array}{c}\text { bent } \\
\text { structure } \\
\text { or not }\end{array}$ \\
\hline & 12.3 & $?$ & f. & 12.3 & 0.5 & 2 & $\left(2 \sigma_{u}\right)^{-1}\left(2 \pi_{g}\right)^{1}$ & ${ }^{3} \Pi_{u}$ & be. \\
12.7 & 12.7 & bu. & a. & 12.3 & 0.5 & 2 & $\left(2 \sigma_{u}\right)^{-1}\left(2 \pi_{g}\right)^{1}$ & ${ }^{1} \Pi_{u}$ & be. \\
13.2 & 13.4 & bu. & a. & 13.8 & 0.7 & 3 & $\left(3 \sigma_{g}\right)^{-1}\left(3 \pi_{u}\right)^{1}$ & ${ }^{1} \Pi_{u}$ & $?$ \\
& 14.2 & bu. & f. & 14.2 & 0.5 & 3 & $\left(3 \sigma_{g}\right)^{-1}\left(3 \pi_{g}\right)^{1}$ & ${ }^{1} \Pi_{g},{ }^{3} \Pi_{g}$ & be. \\
14.7 & & bu. & a. & 15.1 & 0.7 & 4 & $\left(3 \sigma_{g}\right)^{-1}\left(4 \pi_{u}\right)^{1}$ & ${ }^{1} \Pi_{u}$ & $?$ \\
17.4 & 17.5 & not & a. & 17.5 & 0.95 & 5 & $\left(2 \sigma_{u}\right)^{-1}\left(5 \sigma_{g}\right)^{1}$ & ${ }^{1} \Sigma_{u}$ & not \\
19.5 & 19.4 & not & a. & 20.0 & 0.9 & 3 & $\left(2 \sigma_{g}\right)^{-1}\left(3 \sigma_{u}\right)^{1}$ & ${ }^{1} \Sigma_{u}^{+}$ & not \\
\hline
\end{tabular}

higher orbitals, too, higher $\pi_{g}$ orbitals cause a bent structure and those of $\sigma_{g}$ and $\sigma_{u}$ correspond to the linear structure.35) Then we supposed that the bundle of autoionizing states appear in the I. E. C. 's, De and $\mathrm{D} \nu$, when the $\pi_{g}$ orbital participates in the 

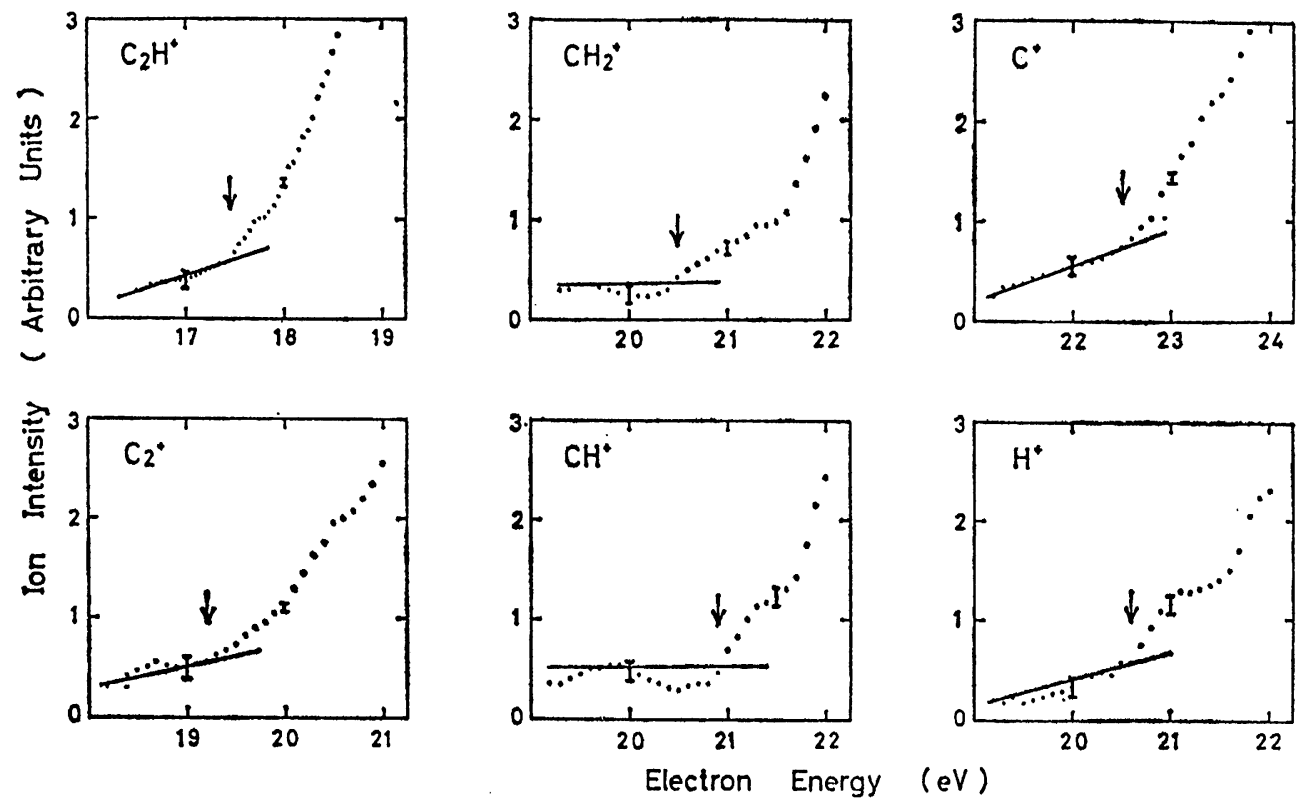

Fig. 3: Ionization efficiency curves for fragment ions from $\mathrm{C}_{2} \mathrm{H}_{2}$ near their appearance thresholds. Bars denote statistical errors.

electronic excited state causing the autoionization. (Although we cannot rule out the possibility at present that the bundle of autoionizing states may be composed of various electronic excited states, the bundle is assumed to consist of various vibrational states in only one electronic state.)

Any clear structures were not observed near $17.5 \mathrm{eV}$ in the I.E.C. of $\mathrm{C}_{2} \mathrm{H}_{2}{ }^{+}$only. However the total I.E.C. shows an upward break at $17.45 \mathrm{eV}$. This break is caused by the contribution of $\mathrm{C}_{2} \mathrm{H}^{+}$formation which gives the A.P. at $17.45 \mathrm{eV}$ (see the following section). The structure at that energy in the De (shown in Fig. 2) corresponds to this break. The $\mathrm{D} \nu$ also shows a plateau covering from $17.4 \mathrm{eV}$ to ${ }^{2} \Sigma_{u}$ state of 18.35
eV. Momigny et al. reported a state at $17.43 \mathrm{eV}$ by differentiation of the I. E. C. of $\mathrm{C}_{2} \mathrm{H}_{2}{ }^{+}$. 19) As seen in Table 2, the state at $17.5 \mathrm{eV}$ is supposed to be an autoionizing state. The state is presumed to interact with ionic state of repulsive potential rather than that of stable potential.

No one has reported an autoionizing state at $19.4 \mathrm{eV}$. The increase at the energy appears clearly in the $\mathrm{De}$, and $\mathrm{D} \nu$ shows a slightly increasing trend.

\subsection{Appearance Potentials for Fragment lons}

Using the vanishing current method, Kusch et al.,20) Coats et al.21) and Franklin et al.22-24) measured the A. P. 's for fragment ions produced from $\mathrm{C}_{2} \mathrm{H}_{2}$ by electron 
impact. Recently Momigny et al. obtained the A. P. 's by use of the curve derived from the differentiation of I.E.C.'s for the ions.19) The I.E.C.'s for all the possible ions including $\mathrm{CH}_{2}{ }^{+}$measured in the present study are shown in Fig. 3.

Although the line denoting a noise level is not always horizontal, the noise level indicated in Fig. 3 seems adequate on account of the size of statistical errors. Thus the value of A.P. proposed in this study is assumed to be the upper limit of the A. P.

The A. P. 's obtained from Fig. 3 are listed in Table 3 with results obtained by other investigators. Dibeler et al. provided the accurate value of the A.P. for $\mathrm{C}_{2} \mathrm{H}^{+}$on the basis of the result of P.I.M. without the interference of hot baud.11) All investigators except Momigny et al. proposed the values for this A.P. in agreement with one another within the experimental errors. Franklin et al. offered the value of A.P. for $\mathrm{C}_{2}{ }^{+}$ which is lower than our value. 23) The values of this A. P. by others are higher than our value by about $4 \mathrm{eV}$. With respect to the A. P. 's for $\mathrm{CH}^{+}, \mathrm{C}^{+}$and $\mathrm{H}^{+}$, our values are consistently lower than others by $1-2 \mathrm{eV}$. These facts suggest that the conventional methods, such as V.C., do not always provide accurate A.P.'s, in contrast to M. E. I.

The value of the A. P. for $\mathrm{CH}_{2}{ }^{+}$in this study is a little lower than that by Franklin et al. who were the only group having reported this A.P.24) There are possibilities that $\mathrm{CH}_{2}{ }^{+}$(m/e 14) was produced from impurities and that $\mathrm{CH}^{+}$including ${ }^{13} \mathrm{C}$ disturbed the measurement of this A.P. However, the A.P.'s for $\mathrm{CH}_{2}{ }^{+}$from the molecules imaginably contained as impurity, e. g., $\mathrm{CH}_{4}, \mathrm{C}_{2} \mathrm{H}_{4}$ and $\mathrm{C}_{2} \mathrm{H}_{6}$, are much lower and that of $\mathrm{N}^{+}$(m/e 14) from residual gas $\mathrm{N}_{2}$ is much higher than this A.P. listed in Table 2. 25, 26, 38) The A.P. for $\mathrm{CH}^{+}$is higher than this A.P. The intensity ratio of $\mathrm{m} / \mathrm{e}$

Table 3: Appearance potentials of fragment ions from $\mathrm{C}_{2} \mathrm{H}_{2}$ (in units of eV). First Deriv. indicates a technique to obtain information from the first derivative curve of the I.E.C.

V.C. indicates the vanishing current method.

\begin{tabular}{|c|c|c|c|c|c|c|}
\hline worker & $\begin{array}{l}\text { Dibeler } \\
\text { et al. }\end{array}$ & $\begin{array}{l}\text { Momigny } \\
\text { et al. }\end{array}$ & Kusch et al. & $\begin{array}{l}\text { Franklin } \\
\text { et al. }\end{array}$ & Coats et al. & $\begin{array}{c}\text { Present } \\
\text { Authors }\end{array}$ \\
\cline { 2 - 6 } method & P.I.M. & $\begin{array}{l}\text { First } \\
\text { Deriv. }\end{array}$ & V. C. & V. C. & V. C. & M. E. I. \\
\hline $\mathrm{C}_{2} \mathrm{H}^{+}$ & $17.36 \pm 0.01$ & 18.41 & $17.8 \pm 0.2$ & 17.3 & $17.8 \pm 0.5$ & $17.45 \pm 0.1$ \\
$\mathrm{C}_{2}{ }^{+}$ & & 23.6 & $23.8 \pm 0.3$ & 18.2 & $23.3 \pm 0.5$ & $19.2 \pm 0.2$ \\
$\mathrm{CH}_{2}{ }^{+}$ & & & & 21 & & $20.5 \pm 0.2$ \\
$\mathrm{CH}^{+}$ & & 23.1 & $22.2 \pm 0.5$ & 21.68 & & $20.9 \pm 0.2$ \\
$\mathrm{C}^{+}$ & & 24.3 & $24.5 \pm 1.0$ & & & $22.5 \pm 0.3$ \\
$\mathrm{H}^{+}$ & & & $21.7 \pm 1.0$ & & & $20.6 \pm 0.3$ \\
\hline Ref. & 11 & 19 & 20 & 23.24 & 21 & -- \\
\hline
\end{tabular}


13 to 14 observed at $23 \mathrm{eV}, 1: 0.2$, is quite different from the one derived on the assumption that the ion of $\mathrm{m} / \mathrm{e} 14$ is composed of only the $\mathrm{CH}^{+}$including ${ }^{13} \mathrm{C}$. Therefore we concluded that the value of $20.5 \mathrm{eV}$ is the A.P. for the $\mathrm{CH}_{2}{ }^{+}$which was produced from $\mathrm{C}_{2} \mathrm{H}_{2}$ through the rearrangement of hydrogen atoms accompanying the breaking of C-C bond.

\section{References}

1) R. S. Mulliken. Can. J. Chem., 36 (1958) 10.

2) W. E. Palke and W. N. Lipscomb, J. Am.Chem. Soc., 88 (1966) 2384.

3) R. J. Buenker, S. D. Peyerimhoff and J. L. Whitten, J. Chem. Phys., 46 (1967) 2029.

4) E. Clementi and H. Popkie, J. Chem. Phys., 57 (1972) 4870.

5) C. Fridh, L. Åsbrink and E. Lindholm, Chem. Phys. Letteers, 15 (1972) 282.

6) C. Baker and D. W. Turner, Proc. Roy. Soc., 308A (1968) 19.

7) A. J. C. Nicholson, J. Chem. Phys., 43 (1965) 1171.

8) V. H. Dibeler and R. M. Reese, J. Res. Natl. Bur. Std., 68 (1964) 409.

9) R. Botter, V.H. Dibeler, J. A. Walker and H. M. Rosenstock, J. Chem. Phys., 44 (1966) 1271.

10) V. H. Dibeler and J. A. Walker, Int. J. Mass Spectrom. Ion. Phys., 11 (1973) 49.

11) V. H. Dibeler, J. A. Walker and K. E. M. Mc Culloh, J. Chem. Phys., 59 (1973) 2264.

12) B. Brehm, Z. Naturforsch., 21a (1966) 196.

13) I. Omura, T. Kaneko, Y. Yamada and K. Tanaka, J. Phys. Soc. Japan, 27 (1969) 178.

14) J. H. Collins, R. E. Winters and G. G. Engerholm, J. Chem. Phys., 49 (1968) 2469.

15) C. E. Brion, Chem. Phys. Letters, 3 (1969) 9.

16) F. P. Lossing, Int J. Mass Spectrom. Ion Phys., 5 (1970) 190.

17) J. E. Collin, Bull. Soc. Chim.Belg., 71 (1962)
15.

18) C. E. Melton and W. H. Hamill, J. Chem. Phys., 41 (1964) 1469.

19) J. Momigny and E. Derouane, Advan. Mass Spectrom., 4 (1968) 607.

20) P. Kusch, A. Hustrulid and J. T. Tate, Phys. Rev., 52 (1937) 843.

21) F. H. Coats and R.C. Anderson, J. Am. Chem. Soc., 79 (1957) 1340.

22) J. L. Franklin and F. H. Field, J. Am. Chem. Soc., 76 (1954) 1994.

23) F. H. Field, J. L. Franklin and F. W. Lampe, J. Am. Chem. Soc., 79 (1957) 2665.

24) J. L. Franklin and M. S. B. Munson, 10th Symposium on Combustion, (1965) 561.

25) K. Maeda, I. H. Suzuki and Y. Koyama, Int. J. Mass Spectrom. Ion Phys., 14 (1974) 273

26) I. H. Suzuki and K. Maeda, Int. J. Mass Spectrom. Ion Phys. 24 (1977) 147.

27) I. H. Suzuki and K. Maeda, Int. J. Mass Spectrom. Ion Phys., 15 (1974) 281.

28) American Petroleum Institute, Research Project 44, Catalog of Mass Spectral Data, Serial No. 72.

29) R. I. Platzman, Vortex, 23 (1962) 372.

30) H. Nakamura, Chem. Phys. Letters, 33 (1975) 151.

31) P. Marmet, E. Bolduc, and J. J. Quéméner, J. Chem. Phys., 56 (1972) 3463.

32) J. E. Collin and J. Delwiche, Can. J. Chem., 45 (1967) 1883.

33) I. H. Suzuki and K. Maeda, Advan. Mass Spectrom., 7 (in press)

34) W. Lichten, J. Chem. Phys., 37 (1962) 2152.

35) E. W. Greene, Jr., J. Barnard and A. B. F. Duncan, J. Chem. Phys., 54 (1971) 71.

36) G. Herzberg, Molecular Spectra and Molecular Structure (D. van Nostrand Co., Inc., Princeton, N. J., 1967), vol. 3.

37) A. D. Walsh, J. Chem. Soc., (1953) 2288.

38) J. L. Franklin, J. G. Dillard, H. M. Rosenstock, J. T. Herron, K. Draxl and F. H. Field, Natl. Std. Ref. Data Ser., Natl Bur. Std., No. 26 (1969). 